\title{
Política Nacional de Atenção Integral à Saúde das Pessoas Privadas de Liberdade no Sistema Prisional: Uma análise sobre a evolução normativa
}

\author{
National Policy for Comprehensive Health Care for Persons Deprived of Liberty in the \\ Prison System: An analysis of normative evolution
}

Política Nacional de Atención Integral a la Salud de las Personas Privadas de Libertad en el Sistema Penitenciario: Un análisis respecto a la evolución normativa

\section{Nathália Gomes Oliveira de Carvalho ${ }^{1}$}

RESUMO: Objetivo: Verificar quais as mudanças normativas trazidas pela Política Nacional de Atenção Integral à Saúde das Pessoas Privadas de Liberdade no Sistema Prisional (PNAISP), instituída pela Portaria Interministerial $\mathrm{n} . \stackrel{0}{1}$, de 2 de janeiro de 2014 , em relação ao Plano Nacional de Saúde no Sistema Penitenciário (PNSSP), instituído por meio da Portaria Interministerial $n . \stackrel{0}{1.777}$, de 9 de setembro de 2003, a partir da descrição do estado da arte da Assistência à Saúde no âmbito prisional. Método: Desenvolveu-se um estudo analítico-descritivo, de caráter qualitativo, baseado em pesquisa documental, de comparação legislativa, e bibliográfica que recaiu sobre dois marcos fundamentais das políticas públicas de saúde no âmbito do sistema prisional: o Plano, de 2003, e a Política, de 2014. Resultado: A PNAISP nasceu da avaliação de uma década de aplicação do PNSSP, quando se verificou o esgotamento deste modelo, que se mostrou restrito por não contemplar em suas ações, entre outros aspectos, a totalidade do itinerário carcerário. Conclusão: A experiência de 12 anos de PNSSP inspirou a formulação e a implementação da PNAISP, trazendo avanços no acesso das pessoas privadas de liberdade no sistema prisional ao cuidado integral no SUS.

Palavras-chave: Saúde. Pessoas privadas de liberdade. Políticas Públicas de Saúde. Direitos Humanos.

ABSTRACT: Objective: To verify the normative changes brought by the National Policy for Integral Attention to the Health of Persons Deprived of Liberty in the Prison System established by Interministerial Ordinance n. 1, of January 2, 2014, in relation to the National Health Plan Penitentiary System, established through Interministerial Ordinance n. 1.777, dated september 9, 2003, based on the state of the art description of health care in prisons. Method: A qualitative, analytical-descriptive study based on documentary, legislative, and bibliographical research was developed that focused on two fundamental milestones of public health policies within the prison system: the Plan (2003) and the Policy (2014). Result: The Policy was born from the evaluation of a decade of application of the Plan, when it was verified the exhaustion of this model, which was restricted because it did not contemplate in its actions, among other aspects, the entire prison itinerary. Conclusion: The 12 year experience of the National Plan

Mestre em Direitos Humanos e Cidadania pela Universidade de Brasília (UnB). Email: nathaliaagomes@gmail.com. ORCID ID: https://orcid.org/0000-0003-1962-2996 
inspired the formulation and implementation of the Policy, bringing advances in the access of people deprived of their liberty in the prison system to integral care in SUS.

Keywords: Health. Persons deprived of liberty. Public Health Policies. Human Rights.

RESUMEN: Objetivo: Verificar cuáles son los cambios normativos traídos por la Política Nacional de Atención Integral a la Salud de las Personas Privadas de Libertad en el Sistema Penitenciario (PNAISP), instituida por la Portaria Interministerial $n^{\circ}$ 1, de 2 de enero de 2014, en relación con el Plan Nacional de Salud en el Sistema Penitenciario (PNSSP), instituido por la Portaria Interministerial no 1.777, de 9 de septiembre de 2003, a partir de la descripción del estado del arte de la Asisténcia sanitaria en el ámbito penitenciario. Método: Se desarrolló un estudio analitico-descriptivo, de carácter cualitativo, basado en investigación documental, de comparación legislativa, y bibliográfica que recayó sobre dos marcos fundamentales de las políticas públicas de salud en el ámbito del sistema penitenciario: el Plan, de 2003, y la Política, de 2014. Resultado: La PNAISP nació de la evaluación de una década de aplicación del PNSSP, cuando se verificó el agotamiento de este modelo, que se mostró restringido por no contemplar en sus acciones, entre otros aspectos, la totalidad del itinerario carcelario. Conclusión: La experiencia de 12 años de PNSSP inspiró la formulación e implementación de la PNAISP, trayendo avances en el acceso de las personas privadas de libertad en el sistema penitenciario al cuidado integral en SUS.

Palabras Clave: Salud. Personas privadas de libertad. Políticas Públicas de Salud. Derechos Humanos.

\section{Introdução}

De acordo com os dados do Levantamento Nacional de Informações Penitenciárias INFOPEN - dezembro 2014, relatório elaborado pelo Departamento Penitenciário Nacional (DEPEN) que buscou sistematizar as informações sobre a situação das prisões brasileiras e das pessoas encarceradas, o país ultrapassou a marca de 622 mil pessoas privadas de liberdade em estabelecimentos prisionais, atingindo uma taxa de mais de 300 presos para cada 100 mil habitantes (1).

Entre os anos 2000 e 2014 é possível observar que o número de vagas nos presídios brasileiros triplicou. Ainda assim, tem-se que o déficit relacionado à demanda por tais vagas dobrou neste mesmo período. Nesse sentido, ao analisarmos a evolução da taxa de aprisionamento em comparação a toda população nacional, é possível afirmar que o ritmo de crescimento do número de pessoas presas no Brasil é acelerado e se contrapõe às tendências dos países que investiram historicamente em políticas públicas voltadas ao tema (2). 
O sistema prisional brasileiro e tal situação de superencarceramento geram impactos de forma direta na condição de saúde da população carcerária, fato este agravado pela aliança de aspectos socioeconômicos, raciais e culturais. A grande incidência de crimes contra o patrimônio (1) é reveladora do perfil socioeconômico da maioria das pessoas presas, as quais se encontram na base da pirâmide social, com escassas oportunidades de estudo, trabalho, moradia e saúde.

São parcos os estudos relacionados à análise normativa das ações destinadas à população privada de liberdade, especialmente na área da saúde. Isso reflete, em certa medida, a invisibilidade desse grupo social no contexto de políticas públicas no âmbito do Sistema Único de Saúde (SUS).

O processo histórico de consagração do direito à saúde como um direito fundamental e universal, tal qual previsto na Constituição Federal de 1988, teve início em meados da década de 1970, quando da atuação dos movimentos sociais que reivindicavam uma maior participação, proteção e inclusão sociais, além da efetivação dos ideais de cidadania e de justiça (5).

Ganhou destaque, nessa época, o movimento da Reforma Sanitária, responsável pela luta pela democratização da saúde como direito de todos e pela ampliação do conceito de saúde-doença, de forma a considerar a interferência dos determinantes sociais no processo de encarceramento. A 8. a Conferência Nacional de Saúde, realizada em 1986, constituiu um verdadeiro marco na sistematização das propostas desenvolvidas pelo movimento sanitário, as quais foram incorporadas na Carta Magna de 1988, por meio do SUS (6).

Nessa perspectiva, a posição que o conceito de saúde atualmente ocupa no ordenamento jurídico pátrio, como direito fundamental e social, reflete a preocupação peculiar do constituinte com o tema e a sua direta relação com a proteção à dignidade da pessoa humana.

O direito à saúde foi inserido na Constituição Federal 1988 (7) no título destinado à ordem social, integrando, assim, a segunda dimensão (ou geração) dos direitos fundamentais, tendo marcado a evolução do Estado de Direito, de inspiração liberalburguesa, para um novo modelo de Estado e Constituição, denominado Estado Social ou Estado Social de Direito (8). 
O art. 6ำ da Carta Magna (7), de forma genérica, estabelece como direitos sociais fundamentais a educação, a saúde, o trabalho, o lazer, a segurança, a previdência social, a proteção à maternidade e à infância. Ainda, o art. 196 (7) reconhece a saúde como direito de todos e dever do Estado, garantido mediante políticas sociais e econômicas que visem à redução do risco de doenças e de outros agravos e ao acesso universal e igualitário às ações e aos serviços destinados à sua promoção, proteção e recuperação (9).

O art. 198 da Constituição Federal (7) prevê como diretrizes do SUS: "I descentralização, com direção única em cada esfera de governo; II - atendimento integral, com prioridade para as atividades preventivas, sem prejuízo dos serviços assistenciais; e III - participação da comunidade".

Não obstante as disposições constitucionais elencadas, os procedimentos para o adequado funcionamento do SUS, bem como as atribuições específicas dos órgãos a ele ligados, somente se efetivaram a partir da elaboração de normas específicas relacionadas à temática da saúde. Nesse sentido, as Leis n.ํ 8.080 (10) e 8.142 (11), ambas de 1990, além de consagrarem a máxima de que a "saúde é direito de todos e dever do Estado", instituíram e normatizaram o SUS no país (9).

Assim, ao reconhecer a saúde como direito social fundamental, o Estado obrigouse não somente a ações, prestações positivas à população, mas também à formulação de políticas públicas sociais e econômicas destinadas à sua promoção, proteção e recuperação.

Entende-se como política de saúde a resposta de uma organização à sociedade diante das condições de saúde dos indivíduos e das populações e seus determinantes, bem como em relação à produção, gestão e regulação de bens e serviços que afetam a saúde e o ambiente. Portanto, política de saúde envolve estudos sobre o papel do Estado, a relação Estado-sociedade, as reações às condições de saúde da população, por intermédio de propostas para a ação pública. Inclui também o estudo de sua relação com políticas econômicas e sociais, controle social, economia da saúde e financiamento (12).

Ao longo da história, verificou-se um distanciamento entre as propostas da política social e da política prisional. A postura do Estado sempre foi a de priorizar ações 
repressivas, ou seja, ações não educativas e pouco integradoras para as pessoas em situação de privação de liberdade e conflito com a lei (13).

As pessoas privadas de liberdade, apesar da perda do direito de ir e vir, conservam seus demais direitos fundamentais, que deverão ser protegidos e garantidos pelo Estado, especialmente pelo fato de essas pessoas estarem legalmente sob sua custódia (14).

Os agravos em saúde que acometem a população geral não apenas são também encontrados no sistema prisional, como o são de maneira potencializada devido às condições precárias de grande parte das unidades prisionais, além do fenômeno do superencarceramento, como dito. Portanto, é crucial que tais políticas públicas sejam interdisciplinares e transversais, de modo a atender a todos, quaisquer sejam as suas especificidades (14).

O crescimento dos índices de encarceramento e as questões relacionadas à desigualdade social, então, tencionaram as instituições para a elaboração de políticas sociais que visam melhorar as condições de vida no sistema carcerário. A questão da saúde prisional, portanto, se apresenta como um desafio para os gestores públicos e para o sistema de justiça.

No que se refere à saúde, nas últimas décadas, o Estado desenvolveu políticas públicas direcionadas especificamente para essa população que foi objeto de análise em investigação desenvolvida para tal fim, quais sejam: o PNSSP, de 2003 e a PNAISP, de 2014 (15).

A Política Nacional de Atenção Integral à Saúde das Pessoas Privadas de Liberdade no Sistema Prisional (PNAISP) nasceu da avaliação de uma década de aplicação do Plano Nacional de Saúde no Sistema Penitenciário (PNSSP), quando se verificou o esgotamento deste modelo, em razão de este ter se mostrado restrito por não contemplar em suas ações, entre outros aspectos, a totalidade do itinerário carcerário.

Diante do cenário apresentado, nasceu a seguinte pergunta de pesquisa: quais as mudanças normativas trazidas pela PNAISP, instituída pela Portaria Interministerial $n .^{\circ}$ 1, de 2 de janeiro de 2014 (3), em relação ao PNSSP, instituído por meio da Portaria Interministerial $\mathrm{n} .{ }^{\circ}$ 1.777, de 9 de setembro de 2003 (4)?

Visando a resposta da pergunta proposta, a partir da descrição do estado da arte da Assistência à Saúde no âmbito prisional, a pesquisa foi orientada pela hipótese de 
que a PNAISP trouxe avanços na atenção a essa população vulnerável, tendo em vista a previsão de ampliação das ações de saúde do SUS.

\section{Metodologia}

Desenvolveu-se um estudo analítico-descritivo comparativo, de caráter qualitativo, baseado em pesquisa legislativa e bibliográfica sobre as políticas públicas de saúde no âmbito do sistema prisional.

Para análise comparativa legislativa, recolheu-se da do portal Saúde Legis (http://portal2.saude.gov.br/saudelegis/leg norma pesq consulta.cfm), o inteiro teor dos

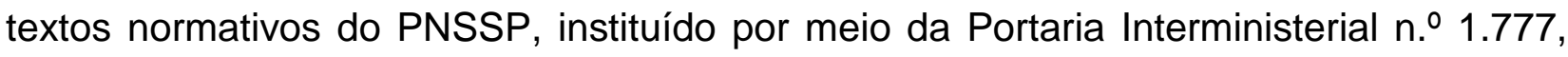
de 9 de setembro de 2003 (4) e da PNAISP, instituída pela Portaria Interministerial n. $\stackrel{1}{1}$, de 2 de janeiro de 2014 (3), fontes primárias da pesquisa.

Após a leitura do inteiro teor das normas, utilizou-se de metodologia comparativa, organizando os principais aspectos do PNSSP e da PNAISP em um quadro, a fim de apresentar com mais clareza as mudanças dos respectivos diplomas legais.

Por se tratar de investigação documental, o projeto não foi submetido ao Comitê de Ética em Pesquisa, estando dispensado da submissão.

\section{Resultados e Discussão}

O atendimento em saúde para pessoas privadas de liberdade está previsto na Lei de Execução Penal (LEP) - Lei n.o 7.210, de 11 de julho de 1984 (16) -, embora tenha se consagrado apenas em 2003 a necessidade de organização de ações e de serviços de saúde no sistema penitenciário baseados nos princípios e diretrizes do SUS (17).

Segundo a LEP (16), a execução penal tem por finalidade proporcionar condições para a harmônica integração social da pessoa sentenciada e da internada, apontando como base do cumprimento das penas privativas de liberdade e restritivas de direitos um programa individualizador da pena (17).

Ainda, em seu art. 14 (16), prevê que a assistência à saúde do preso e do internado de caráter preventivo e curativo, deve compreender atendimento médico, farmacêutico e odontológico. Fica, portanto, demonstrada, na forma da lei, a 
responsabilidade estatal na defesa do acesso à saúde das pessoas privadas de liberdade.

O PNSSP foi fruto do trabalho construído com a colaboração de diversas áreas técnicas dos Ministérios da Saúde e da Justiça e com a participação do Conselho Nacional de Secretários de Saúde, do Conselho Nacional de Secretários Municipais de Saúde e do Conselho Nacional de Política Criminal e Penitenciária. Aprovado na Comissão Intergestores Tripartite, na $12 .^{\circ}$ Conferência Nacional de Saúde, no Conselho Nacional de Política Criminal e Penitenciária (Ministério da Justiça), sendo incluído no Plano Nacional de Saúde (18).

Considerado um marco na atenção em saúde voltada para a população privada de liberdade, o Plano teve como objetivo prover atenção integral à saúde da população prisional, contribuir para o controle e/ou redução dos agravos mais frequentes à saúde da população penitenciária brasileira, a partir de um elenco mínimo de procedimentos no âmbito da promoção da saúde, prevenção de agravos e assistência, e aproximar a população prisional ao SUS, buscando garantir que o direito à saúde se efetivasse a partir de uma perspectiva de direitos humanos e cidadania (19).

Enquanto a LEP (16) cita a "assistência" ao "preso", o Plano abarca a promoção da saúde ao aludir à atenção integral à população prisional, ainda que recorte a população penitenciária, pois contemplou aqueles recolhidos nas unidades masculinas, femininas e psiquiátricas, conforme disposto no art. 1. da Portaria instituidora do respectivo Plano.

O planejamento das ações de atenção básica oferecidas por equipes multiprofissionais que atuam "in loco" nas unidades prisionais não contemplava a totalidade do itinerário carcerário, ou seja, as penitenciárias federais, as delegacias, as cadeias públicas, os distritos policiais (14), os presos do regime aberto e os presos provisórios (18).

Destarte, ao dar uma maior ênfase na prevenção da saúde e na inclusão da promoção da saúde como prioridade para fazer frente à insalubridade e à superlotação no sistema prisional, o plano significou avanço em vários aspectos em relação à LEP.

Na época do Plano estava em vigor a Norma Operacional de Assistência à Saúde (NOAS), instituída pela Portaria n. 373/2002, do Ministério da Saúde, revogada pela

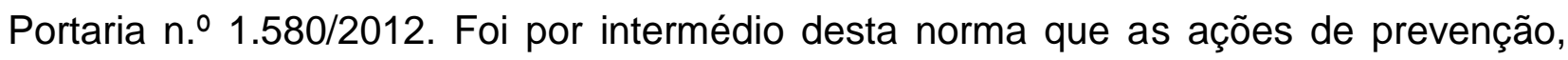


promoção e assistência foram elencadas como linhas de ação, constantes do Anexo 1, item 3.

Dividido em ações de atenção básica, ações de média complexidade e ações complementares, a assistência passou a ser guiada pela lógica da atenção básica, qual seja, a prevenção e a promoção em saúde enquanto atividades prioritárias, bem como o investimento em grupos de risco reunidos com base em instrumentos epidemiológicos de aferição da prevalência e incidência de doenças e agravos. Essa perspectiva surgiu do consenso que emergiu ao longo dos últimos anos sobre o sistema prisional: a insalubridade e a superlotação, estruturantes desse sistema, tornam as unidades prisionais espaços propícios à difusão de inúmeras doenças infecto-contagiosas (17).

O Plano traça, portanto, o elenco mínimo de procedimentos no âmbito da promoção da saúde, prevenção de agravos e assistência em unidades de saúde do sistema prisional, no nível de atenção básica e de média complexidade e ações complementares, destacando-se o controle da tuberculose; da hipertensão e diabetes; da dermatologia sanitária - hanseníase; a saúde Bucal; a saúde da mulher; o diagnóstico, aconselhamento e tratamento em doenças sexualmente transmissíveis (DST) e HIV/AIDS; a assistência farmacêutica básica, as imunizações e a coleta de exames laboratoriais.

No tocante às competências, elas são compartilhadas entre o Ministério da Saúde, responsável pela gestão do Plano em âmbito federal; o Ministério da Justiça; as Secretarias Estaduais de Saúde; as Secretarias Estaduais de Justiça ou correspondentes e as Secretarias Municipais de Saúde, de acordo com o Anexo 1, item 8.4 do PNSSP. Ou seja, a gestão das ações e serviços de saúde no sistema penitenciário passou a ser de incumbência dos órgãos de saúde das três esferas de governo e as ações preventivas passaram a ser prioridade, em consonância com a Constituição Federal (17).

Por intermédio de um termo de adesão, os Estados da Federação interessados em organizar a atenção à saúde com base no referido Plano solicitam ao governo federal a adesão a partir da elaboração de um Plano Operativo Estadual (POE) para, em seguida, aprová-lo em seu Conselho Estadual de Saúde (CES), consoante disposto no art. $2 .^{\circ}$ do PNSSP. 
Apenas os Estados qualificados, ou seja, que submetem o POE à avaliação do Ministério da Saúde, recebem o incentivo financeiro federal para custeio das ações de cada uma das Equipes de Atenção à Saúde no Sistema Penitenciário (EPENs) instaladas nos estabelecimentos penais (19).

A nível do PNSSP, o financiamento das ações de saúde passou a ser compartilhado entre os órgãos gestores da saúde e da justiça das esferas de governo. Para tanto, criou-se o Incentivo para a Atenção à Saúde no Sistema Penitenciário, cabendo ao Ministério da Saúde financiar o correspondente a $70 \%$ do recurso e ao Ministério da Justiça o correspondente a $30 \%$, conforme artigos $4 .^{\circ}$ e $5 . .9$ do PNSSP.

Tal incentivo financia as ações de promoção da saúde e de atenção básica relativa às ações de atenção básica, de média complexidade e ações complementares anteriormente elencadas (art. 5ำ $3^{\circ}$ do PNSSP).

O incentivo corresponde ao número de pessoas presas nas unidades prisionais. Em unidades acima de 100 pessoas presas, serão implantadas equipes de saúde (EPENs) - uma equipe para até 500 presos, com incentivo de $R \$ 40.008,00$ /ano por equipe implantada. Em unidades com número de até 100 pessoas presas, as ações e serviços de saúde serão realizadas por profissionais da Secretaria Municipal de Saúde, a qual será repassado Incentivo no valor de $\mathrm{R} \$ 20.004 /$ ano por estabelecimento prisional (art. $5^{\circ}, \S \$^{\circ}$ e $2^{\circ}$ do PNSSP).

Ressalta-se que, para além dos recursos que compõem o incentivo citado, coube ao Ministério da Justiça alocar recursos financeiros da reforma física e na aquisição de equipamentos para os estabelecimentos de saúde das unidades prisionais (art. 6 do PNSSP).

Segundo os indicadores de avaliação², entre 2003 e 2013, o Plano se mostrou bem sucedido ainda que tenha deixado a desejar no critério número de EPENs no território nacional, cuja cobertura da assistência atingiu de 25\% a 30\% da população - 304 EPENs em até 562 estabelecimentos penais registrados até junho de 2012. No tocante

\footnotetext{
2 Dados do estudo desenvolvido por Martinho Silva, pesquisador das políticas públicas voltadas à saúde mental e, especialmente, dirigida à população em cumprimento de medida de segurança em hospitais de custódia e tratamento. A obra intitulada "Do Plano à Política: garantindo o direito à saúde para todas as pessoas do sistema prisional", é resultado da pesquisa desenvolvida entre 2011 e 2013, no Programa de Direito Sanitário da Diretoria Regional de Brasília da Fundação Oswaldo Cruz (PRODISA - Fiocruz Brasília). Trata- se de uma ação conjunta da Área Técnica de Saúde no Sistema Penitenciário do Departamento de Ações Programáticas e Estratégicas na Secretaria de Atenção à Saúde do Ministério da Saúde e do Departamento Penitenciário Nacional do Ministério da Justiça.
} 
ao processo de qualificação dos Estados federados, a adesão foi de 26 dos 27 Estados qualificados (19).

Durante o processo de avaliação do Plano, em 2011, houve um crescimento da população prisional, em especial do encarceramento feminino. Quando o PNSSP foi lançado, estimava-se a população prisional no País em 230 mil, enquanto os últimos dados disponibilizados pelo INFOPEN apontam para um crescimento acelerado. Assim, a oferta de ações e serviços de saúde para a população carcerária ficou mais difícil de ser planejada bem como a previsão de alocação de recursos (19).

Esse panorama apontou para a necessidade de elaboração de uma política pública de saúde para o sistema prisional que abarcasse todo o itinerário carcerário e que se conectasse aos serviços da Rede de Atenção à Saúde do SUS.

A política prisional, nas palavras de Silva, deve ter em mente três fatores interrelacionados: 1) déficit de vagas; 2) tratamento penitenciário, reintegração social e apoio ao egresso; e 3) redução do encarceramento e alternativas penais (19).

A PNASP nasce, portanto, da avaliação de uma década de aplicação do PNSSP, momento em que se constatou o esgotamento deste modelo e a necessidade de promoção da inclusão efetiva das pessoas privadas de liberdade ao SUS, cumprindo os princípios de universalidade e de equidade, consagrados nos artigos 196 da Constituição Federal de 1988 (14).

Construída de forma democrática e participativa, a sua elaboração contou com a presença de gestores, de trabalhadores em serviços penais, da academia e da sociedade civil organizada, tendo sido pactuada na Comissão Intergestores Tripartite (CIT), deliberada pelo Conselho Nacional de Saúde (CNS), acolhida favoravelmente pelo Conselho Nacional de Secretários de Justiça (CONSEJ) e pelo Conselho Nacional de Política Criminal e Penitenciária (CNPCP) (14).

As situações de confinamento, de insalubridade e de superlotação foram levadas em conta na Política que caminhou positivamente para incluir os trabalhadores em serviços penais, familiares e demais pessoas que se relacionam com as pessoas encarceradas nas ações de promoção da saúde e de prevenção de agravos no âmbito da Política (art. 8.ำ da PNAISP). 
Conforme disposto nos arts. 2.ำ e 7. da PNAISP, são pessoas privadas de liberdade e beneficiárias da Política, aquelas com idade superior a 18 (dezoito) anos e que estejam sob a custódia do Estado em caráter provisório ou sentenciados para o cumprimento de pena privativa de liberdade ou medida de segurança. Entende-se por sistema prisional, portanto, para fins desta Política, todo o itinerário carcerário, desde o momento da detenção e da condução para um estabelecimento policial até a término do cumprimento da pena (14).

O Plano não contempla nem financia serviços que não sejam voltados exclusivamente para as pessoas privadas de liberdade, fazendo com que esses agentes fiquem sob o encargo de Estados e Municípios. Isto é, age exclusivamente sobre a pessoa privada de liberdade sem incluir, como estratégia, a comunidade prisional como um todo, deixando a critério de cada Estado ou Município da Federação uma capacitação da EPEN que atente para essa ação (19).

Com a PNAISP, passou-se a considerar efetivamente os agravos e doenças da população prisional como um problema de saúde pública, estendendo a atividade de prevenção àqueles que convivem com a população confinada em locais insalubres e superlotados (19).

Sucedendo a NOAS, tivemos o advento do Pacto pela Saúde, em 2006, (Portaria Ministerial no 399, de 22 de fevereiro de 2006) (20), conjunto de reformas institucionais do SUS pactuado entre as três esferas de gestão (União, Estados e Municípios) com o objetivo de promover inovações nos processos e instrumentos de gestão, visando alcançar maior eficiência e qualidade das respostas do Sistema Único de Saúde (21).

Em que pese não ter implicado diretamente em normativas vinculadas ao tema da saúde prisional, instituiu um conjunto de dispositivos estratégicos que fortaleceram o processo de pactuação intergestores e impactaram na redefinição das responsabilidades de cada gestor em função das necessidades de saúde da população e na busca da equidade social (21).

A oferta das demais ações/serviços será prevista e pactuada na Rede de Atenção em Saúde (RAS), instituídas pelo Decreto n. ${ }^{\circ} 7.508 / 2011$, que passa a orientar as atividades sanitárias no plano administrativo (19). A promoção do acesso à RAS, visando o cuidado integral, está disposto no art. 6.․․ inciso I da PNAISP. 
Nesse sentido, o art. 10 prevê que os serviços de saúde nas unidades prisionais serão estruturados como pontos de atenção da RAS e cadastrados no Sistema Cadastro Nacional de Estabelecimentos de Saúde (SCNES).

No contexto da PNAISP, as ações de saúde serão ofertadas por serviços e equipes interdisciplinares. À nível da atenção básica, será ofertada pelas equipes das Unidades Básicas de Saúde (UBS) definidas no território ou por meio das Equipes de Saúde no Sistema Prisional (ESP), observada a pactuação estabelecida (art. 9ำ da PNAISP).

Cabe ressaltar que as equipes atuarão nos complexos penitenciários e/ou nas unidades prisionais com população superior a 1.000 (mil) pessoas privadas de liberdade e será regulamentada por ato específico do Ministro de Estado da Saúde (art. 9º, § único da PNAISP). Essa previsão normativa aparenta contribuir no sentido de favorecer a redução dos deslocamentos das pessoas privadas de liberdade.

A adesão à Política se dá pela pactuação do Estado e do Distrito Federal com a União mediante a observância da assinatura do Termo de Adesão (Anexo I da PNAISP); elaboração de Plano de Ação Estadual para Atenção à Saúde da Pessoa Privada de Liberdade (Anexo II da PNAISP) e encaminhamento da referida documentação ao Ministério da Saúde para aprovação (art. 13 da PNAISP). Importante ressaltar, no que tange ao Município, que a adesão será facultativa e deve observar a adesão estadual à PNAISP (art. 14 da PNAISP).

O financiamento da PNAISP sofreu alteração quando comparado ao Plano, não havendo mais a previsão em porcentagens entre o Ministério da Saúde e o Ministério da Justiça.

Nos termos da Política, as fontes são compartilhadas e proveem dos entes da Federação (União, Estados e Municípios) e do Ministério da Saúde e da Justiça, diferenciando-se no que tange à atenção especializada em saúde, que deveria ser predominantemente estadual. A gestão fica a cargo do Estado ou do Distrito Federal e a execução do Município, de modo que a gestão das ações e serviços de saúde no sistema prisional se mantivesse no mesmo nível de gestão pela custodia e tratamento da população carcerária: o Estado ou o Distrito Federal (19). 
Compete à União, por intermédio do Ministério da Saúde, garantir fontes de recursos federais para compor o financiamento de programas e ações na rede de atenção à saúde nos Estados, Distrito Federal e Municípios, transferindo de forma regular e automática, os recursos ao Fundo Nacional de Saúde (art. 15, inciso I, alínea c da PNAISP).

Ressalta-se que a competência de apoiar, técnica e financeiramente, a construção, a ampliação, a adaptação e o aparelhamento das unidades básicas de saúde, exclusiva do Ministério da Justiça no contexto do Plano, passou a ser compartilhada com o Ministério da Saúde (art. 15, inciso I, alínea n da PNAISP).

O Ministério da Justiça permaneceu com a competência para assistir técnica e financeiramente na construção, na reforma e no aparelhamento do espaço físico necessário à unidade de saúde dentro dos estabelecimentos penais, na forma do art. 15, inciso II, alínea f da PNAISP.

O monitoramento e a avaliação da Política, dos serviços, das equipes e das ações de saúde passaram a ser de competência de ambos os Ministérios, por meio da inserção de dados e documentos nos sistemas de informação da atenção à saúde (art. 18 da PNAISP).

Por fim, com o objetivo de ilustrar a evolução normativa descrita da Política frente ao Plano, segue quadro comparativo.

Quadro 1. Quadro comparativo: Do Plano à Política.

\begin{tabular}{|c|c|}
\hline PNSSP & PNAISP \\
\hline $\begin{array}{l}\text { Aprova o Plano Nacional destinado a prover } \\
\text { a atenção integral à saúde da população } \\
\text { prisional confinada em unidades masculinas } \\
\text { e femininas, bem como nas psiquiátricas (art. } \\
1^{\circ} \text { ), não contemplando a totalidade do } \\
\text { itinerário carcerário. }\end{array}$ & $\begin{array}{l}\text { Institui a Política Nacional de Atenção Integral à } \\
\text { Saúde das Pessoas Privadas de Liberdade no } \\
\text { Sistema Prisional (PNAISP) no âmbito do } \\
\text { Sistema Único de Saúde (SUS) (art. } 1^{\circ} \text { ). } \\
\text { Amplia o rol de beneficiários. As pessoas que se } \\
\text { encontram sob custódia do Estado inseridas no } \\
\text { sistema prisional ou em cumprimento de medida } \\
\text { de segurança (art. } 7^{\circ} \text { ), os trabalhadores em } \\
\text { serviços penais, os familiares e demais pessoas } \\
\text { que se relacionam com as pessoas privadas de } \\
\text { liberdade serão envolvidos em ações de } \\
\text { promoção da saúde e de prevenção de agravos } \\
\left.\text { no âmbito da Política (art. } 8^{\circ}\right) \text {. }\end{array}$ \\
\hline
\end{tabular}


Nas unidades prisionais com até 100 presos, o atendimento será realizado no próprio estabelecimento por profissionais da Secretaria Municipal de Saúde. Nas unidades prisionais acima de 100 presos, a implementação de equipes de saúde leva em consideração uma equipe para até 500 presos (art. 8).

A adesão ao Plano se dá com a formulação do Plano Operativo Estadual, na forma do Anexo II da Portaria instituidora (art. $2^{\circ}$ ). Caso o Município assuma a gestão, deverá constar do Plano. Após, encaminha-se para credenciamento, mediante Termo de Adesão. O município só pode pactuar se o Estado tiver pactuado (art. $2^{\circ}, \S^{\circ}{ }^{\circ}$ ).

O financiamento das ações de saúde deverá ser compartilhado entre os órgãos gestores da saúde e da justiça das esferas de governo. (art. $4^{\circ}$ ), cabendo ao Ministério da Saúde financiar o correspondente a $70 \%$ do recurso e ao Ministério da Justiça o correspondente a $30 \%$ do recurso (art. $5^{\circ}$ ).

O Ministério da Justiça alocará recursos financeiros que serão utilizados no financiamento da reforma física e na aquisição de equipamentos para os estabelecimentos de saúde das unidades prisionais (art. 6을

A unidade ou serviço executor das ações deverá desenvolver um elenco de procedimentos necessários ao atendimento no nível da atenção básica e do mínimo da assistência no nível da média complexidade, conforme NOAS/MS.
A oferta de ações de saúde especializada em serviços de saúde localizados em complexos penitenciários e/ou unidades prisionais com população superior a 1.000 (mil) pessoas privadas de liberdade será regulamentada por ato específico do Ministro de Estado da Saúde (art. 9으, § único).

A adesão à Política ocorrerá por meio da pactuação do Estado e do Distrito Federal com a União, sendo observados os seguintes critérios constantes do art. 13.

Não há mais a previsão de incentivo em porcentagens entre o Ministério da Saúde e o Ministério da Justiça.

Nos termos da Política, as fontes são compartilhadas e proveem dos entes da Federação, do Ministério da Saúde e da Justiça.

A competência passou a ser compartilhada com o Ministério da Saúde (art. 15, inciso I, alínea n).

A oferta das ações e serviços de saúde será prevista e pactuada na Rede de Atenção à Saúde (art. 9ํ, II).

\section{Considerações finais}

Um plano é uma forma de dar cumprimento a uma política pública, a partir da sistematização de objetivos, diretrizes, metas e estratégias. Uma política pública é a concretização da ação governamental que envolve questões de ordem pública, com amplo alcance e funções ora distributivas, ora redistributivas e ora regulatórias (22).

Sendo assim, um plano precede uma política e, nesse sentido, o PNSSP, nos seus 12 anos, inspirou a formulação e a implementação da PNAISP, trazendo avanços, no 
aspecto normativo, ao acesso das pessoas privadas de liberdade no sistema prisional ao cuidado integral no SUS, e confirmando, assim, a hipótese de pesquisa.

Considera-se que não há descontinuidade da Política em relação ao Plano, vez que ambos convergem com a universalidade do acesso, a descentralização da gestão e atenção à saúde, a necessidade de participação da comunidade e inclusão social, bem como a proteção e garantia dos direitos humanos.

No tocante aos princípios e diretrizes, também é possível visualizar uma comunicação entre o Plano e a Política, porém somente na Política foi possível enxergá-

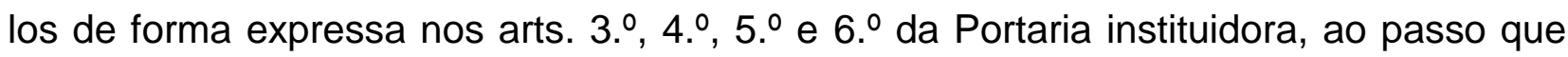
tais aspectos encontram-se implícitos no texto normativo do Plano.

A Política ampliou o escopo da população a ser abrangida pelas ações e serviços de saúde em relação ao previsto pelo Plano (voltado para a população penitenciária, ou seja, os apenados), envolvendo toda a comunidade prisional - presos provisórios, detidos nas delegacias, os trabalhadores que prestam serviços nos estabelecimentos penais e familiares que visitam os presos. Esse avanço foi determinante para que a PNAISP adotasse a nomenclatura da população-alvo da Política as pessoas privadas de liberdade (19).

O aspecto da intersetorialidade passou a ser crucial, sem o qual não é possível ofertar ações e serviços de saúde a pessoas privadas de liberdade em unidades prisionais. Saúde e justiça precisaram articular-se de algum modo, de preferência colaborando para uma composição entre saúde e segurança na oferta de serviços de saúde dentro e fora do ambiente prisional (17).

Para que os obstáculos possam ser minimizados é de suma importância a articulação entre os gestores de saúde e de administração penitenciária, em todos os níveis da federação, de forma a priorizar a garantia dos direitos humanos e a dignidade das pessoas privadas de liberdade, bem como a salubridade, a segurança e a manutenção das ações de saúde daqueles que se encontram recolhidos nas unidades prisionais (14).

As lógicas da saúde, da justiça e da segurança precisam ser negociadas no cotidiano carcerário, respeitando as competências exclusivas de cada setor e mantendo 
uma direção única: a garantia do direito à saúde e a proteção dos direitos humanos das pessoas encarceradas (19).

A PNAISP, fundamentada nos princípios da integralidade e da intersetorialidade, se mostrou mais atenta, no plano normativo, às necessidades dessa população em relação ao PNSSP, porém o grande desafio continua sendo o de assegurar de maneira efetiva o direito constitucional à saúde das pessoas privadas de liberdade.

Desse modo, reconhecendo o limite do escopo da pesquisa, espera-se que as informações e reflexões aqui apresentadas possam servir de subsídio para outros estudos e análises no tocante ao direito à saúde no sistema prisional.

\section{Referências}

1. Departamento Penitenciário Nacional. Ministério da Justiça (BR). Levantamento Nacional de Informações Penitenciárias. Infopen - dezembro 2014. Disponível em: http://www.justica.gov.br/seus-direitos/politicapenal/infopen dez14.pdf/@@download/file; [Acesso em 16. set. 2017].

2. Conselho Nacional de Justiça. Informativo Rede Justiça Criminal. 2016, n. 8. Disponível em: http://www.cnj.jus.br/files/conteudo/arquivo/2016/02/b948337bc7690673a39cb5cdb1099 4f8.pdf; [Acesso em 16. set. 2017].

3. Brasil. Ministério da Saúde. Ministério da Justiça. Portaria Interministerial no 1 de 2 de janeiro de 2014. Institui a Política Nacional de Atenção Integral à Saúde das Pessoas Privadas de Liberdade no Sistema Prisional (PNAISP) no âmbito do Sistema Único de Saúde (SUS). Diário Oficial da União da República Federativa do Brasil. (03 jan 2014); Seção 1, 18-21.

4. Brasil. Ministério da Saúde. Ministério da Justiça. Portaria Interministerial № 1777 de 9 de setembro de 2003. Aprova o Plano Nacional de Saúde no Sistema Penitenciário, constante do Anexo 1, destinado a prover a atenção integral a saúde da população prisional confinada em unidades masculinas e femininas, bem como nas psiquiátricas. Diário Oficial da União da República Federativa do Brasil. (11 ago 2003); Seção 1, 39 43.

5. Teixeira, SMF. Retomar o debate sobre a reforma sanitária para avançar o Sistema Único de Saúde (SUS). Rev. Adm. Empres, 2009, 49 (4): 472-480. São Paulo.

6. Paim, JS. Equidade e Reforma em Sistemas de Serviços de Saúde: o caso SUS. Revista Saúde e Sociedade, 2006, 15 (2): 34-46. São Paulo.

7. Brasil. Constituição da República Federativa do Brasil, 8 de outubro de 1988. Brasília: Senado Federal, 2008.

8. Bonavides, P. Curso de Direito Constitucional. 8.ed., São Paulo: Malheiros; 1998. 
9. Sarlet, IW. Algumas considerações em torno do conteúdo, eficácia e efetividade do direito à saúde na Constituição de 1988. Panóptica, Vitória, ano 1 (4): 1-22, 2006. Disponível em: <http://www.panoptica.org>. [Acesso em: 04. ago. 2017].

10. Brasil. Lei $n^{\circ} 8.080$, de 19 de setembro de 1990. Dispõe sobre as condições para a promoção, proteção e recuperação da saúde, a organização e o funcionamento dos serviços correspondentes e dá outras providências. Brasília, 19 set 1990. Disponível em: http://www.planalto.gov.br/ccivil 03/leis/L8080.htm; [Acesso em 08. ago. 2017].

11. Brasil. Lei $n^{\circ}$ 8.142, de 28 de dezembro de 1990. Dispõe sobre a participação da comunidade na gestão do Sistema Único de Saúde (SUS) e sobre as transferências intergovernamentais de recursos financeiros na área da saúde e dá outras providências. Brasília, 28 de dezembro de 1990. Disponível em:

http://www.planalto.gov.br/ccivil 03/leis/L8142.htm; [Acesso em 08. ago. 2017].

12. Paim JS, Teixeira CF. Política, planejamento e gestão em saúde: balanço do estado da arte. Política e gestão em saúde. Rev Saúde Pública, 2006, 40 (n. Esp): 73-8

13. Cardoso, MCV. As assistências previstas na Lei de Execução Penal: uma tentativa de inclusão social do apenado. Ser Social. Brasília, 2009, 11 (23): 106-128.

14. Ministério da Saúde (BR). Secretaria de Atenção à Saúde. Departamento de Ações Programáticas Estratégicas. Coordenação de Saúde no Sistema Prisional. Política Nacional de Atenção Integral à Saúde das Pessoas Privadas de Liberdade no Sistema Prisional/ Ministério da Saúde, Secretaria de Atenção à Saúde, Departamento de Ações Programáticas Estratégicas, Coordenação de Saúde no Sistema Prisional. Brasília: Ministério da Saúde; 2014.

15. Lermen HS, Gil LB, Cúnico SD, Jesus, LO et al. Saúde no cárcere: análise das políticas sociais de saúde voltadas à população prisional brasileira. Physis Revista de Saúde Coletiva, Rio de Janeiro, 2015, 25(3): 905-924.

16. Brasil. Lei no 7.210, de 11 de julho de 1084. Institui a Lei de Execução Penal. Brasília, 11 de julho de 1984. Disponível em: http://www.planalto.gov.br/ccivil 03/leis/L7210.htm; [Acesso em 08. ago. 2017].

17. Ministério da Saúde (BR). Secretaria de Atenção em Saúde. Departamento de Ações Programáticas Estratégicas. Legislação em saúde no sistema penitenciário / Ministério da Saúde, Secretaria de Atenção em Saúde, Departamento de Ações Programáticas Estratégicas. Brasília : Ministério da Saúde; 2010.

18. Ministério da Saúde (BR). Secretaria de Atenção à Saúde. Departamento de Ações Programáticas Estratégicas. Plano Nacional de Saúde no Sistema Penitenciário / Ministério da Saúde, Secretaria de Atenção à Saúde. Departamento de Ações Programáticas Estratégicas. Brasília: 2.ed. Ministério da Saúde; 2005.

19. Silva MBB. Saúde penitenciária no Brasil: plano e política. Brasília: Verbena Editora; 2015.

20. Brasil. Ministério da Saúde. Ministério da Justiça. Portaria Ministerial nº 399, de 22 de fevereiro de 2006. Divulga o Pacto pela Saúde 2006 - Consolidação do SUS e aprova as Diretrizes Operacionais do Referido Pacto. Diário Oficial da União da República Federativa do Brasil. (23 fev 2006); Seção 1, 43-51. 
21. Ministério da Saúde (BR). Secretaria Executiva. Departamento de Apoio à Descentralização. Coordenação-Geral de Apoio à Gestão Descentralizada. Diretrizes operacionais dos Pactos pela Vida, em Defesa do SUS e de Gestão / Ministério da Saúde, Secretaria Executiva, Departamento de Apoio à Descentralização. CoordenaçãoGeral de Apoio à Gestão Descentralizada. - Brasília: 76 p. - (Série A. Normas e Manuais Técnicos). ISBN 85-334-0960-5.

22. Castro, CLF. Gontijo, CRB. Amabile, AEN. Dicionário de políticas públicas. Barbacena: Ed. UEMG; 2012.

Recebido em: 13.12.2017

Aprovado em: 26.12.2017

\section{Como citar este artigo:}

Carvalho NGO. Política Nacional de Atenção Integral à Saúde das Pessoas Privadas de Liberdade no Sistema Prisional: Uma análise sobre a evolução normativa. Revista Cadernos Ibero-Americanos de Direito Sanitário. 2017 out./dez, 6(4):112-129. 